\title{
Redes sociais e recrutamento \\ O caso dos diretores e presidentes do Banco Central do Brasil (1994-2016)
}

\author{
Renato Monseff Perissinotto, Marco Antonio Ribas Cavalieri, \\ Eric Gil Dantas e Rodolfo Palazzo Dias
}

Apresentação

O senso comum, douto ou não, tende a ver o Banco Central, nos mais diversos países, como uma instituição técnica, cujo insulamento e independência seriam não apenas desejáveis, mas possíveis. Somente desse modo os complexos problemas relativos à gestão da política monetária poderiam ser administrados com "isenção" e acuidade técnica. Muito do que se tem produzido sobre bancos centrais mundo afora no campo das ciências sociais visa a desmistificar essa proposição.

Ainda que se possa considerar que, em função da importância do objeto, a bibliografia produzida sobre ele não seja, em termos quantitativos, tão grande, é possível identificar várias pesquisas consistentes na Europa, nos Estados Unidos e no Brasil. Muito do que se produz toma como objeto central de análise a trajetória profissional e educacional dos dirigentes dos bancos centrais a fim de revelar como o recrutamento de tais dirigentes está longe de ser aleatório, o que permitiria ao menos qualificar a tese da independência dessa instituição.

Em trabalho recente, Adolph (2013) argumenta, com base em análises do processo de recrutamento de policy makers de bancos centrais ao redor do mundo, que tanto a trajetória profissional prévia ao cargo como a perspectiva de posiçôes futuras podem afetar a formação das preferências individuais e, consequentemente, as decisões dos dirigentes sobre política monetária. A perspectiva de ascensão, seja dentro da organização, seja para outra organização, pública ou privada, cria um incentivo 
para que esses dirigentes agradem não só seus superiores diretos, mas qualquer agente que possa ajudar em sua trajetória profissional, podendo impactar em decisões de política econômica. A porta-giratória entre o trabalho na autoridade monetária e as empresas ou outras instituições permitiria questionar "o mito da neutralidade" destes dirigentes.

Göhlmann e Vaubel (2007), autores de um estudo que se debruça sobre os bancos centrais de dez países europeus, o Federal Reserve norte-americano e o próprio Banco Central Europeu, adicionam às carreiras o background educacional dos dirigentes como elemento explicativo de suas decisões. Para eles, tanto a carreira ocupacional quanto a formação educacional afetam o modo pelo qual os dirigentes dos bancos centrais lidam com o problema da inflação exatamente porque são formadoras de “crenças causais” acerca do fenômeno inflacionário ( Göhlmann e Vaubel, 2007).

O estudo de Farvaque et al. (2009) analisou 175 presidentes de nove Bancos Centrais, de 1999 a 2008. Nele fica demonstrado que o tipo de experiência profissional (setor privado, academia, burocracia do próprio Banco Central) dos integrantes dos comitês de política monetária dos principais países da Organização para a Cooperação e Desenvolvimento econômico (OCDE), e mesmo o sexo do dirigente, também impactam sobre as decisões relativas à inflação. Os autores descobriram que há diferentes predomínios de tipos de conselheiros nesses comitês. Por exemplo, o conselho do Banco Central Europeu é dominado por "economistas públicos", enquanto no Banco Central da Austrália, o predomínio é de "economistas do setor privado" e, no Banco do Canadá, predominam "banqueiros centrais" (isto é, com origem interna ao banco).

Vale lembrar também o estudo de Lebaron (2010), que acrescenta o impacto que experiências biográficas distintas têm sobre escolhas políticas, disposições cognitivas e diferenças culturais. Segundo o autor, "os comportamentos dos bancos centrais são, ao menos parcialmente, explicados pelas características dos seus dirigentes, pelo tipo de ativos sociais que acumularam e pelas disposições que acompanham esses ativos" (Lebaron, 2010, p. 298, tradução livre). Seu trabalho aponta para uma presença maior de recrutamento interno aos bancos centrais, sugerindo que, a partir da década de 1980, isso possa ter acontecido em razão de uma valorização da "independência" dessas instituições ${ }^{1}$.

Para o caso dos dirigentes do Banco Central do Brasil ( $\mathrm{BCB})$, as principais pesquisas são as de Loureiro (1997), Novelli (2002) e Olivieri (2007).

O estudo de Loureiro (1997) reconstruiu a origem tanto de diretores como de presidentes do $\mathrm{BCB}$, desde sua criação até 1995 . Tomando apenas o caso dos diretores,

1. No início da década de 1990, Cukierman (1992) reuniu uma extensa literatura sobre a independência dos bancos centrais. 
Loureiro demonstra que entre 1965, primeiro ano de funcionamento da agência, e 1995, marco final do seu estudo, dos 50 diretores que passaram pelo Banco, a maioria tinha sido recrutada dentro da burocracia do próprio Banco (na realidade, nos primeiros anos do Banco eram, em sua maioria, funcionários do Banco do Brasil e da Superintendência da Moeda e do Crédito). Contudo, a apresentação dessas informações de forma muito agregada esconde a mudança no perfil dos diretores recrutados nos diferentes governos após o regime ditatorial-militar (1964-1985).

Novelli (2002) sublinha que o governo Figueiredo (1979-1985) marcou uma mudança decisiva nos quadros do $\mathrm{BCB}$, que deixaram de ser ocupados predominantemente por funcionários da própria instituição. A partir daí, houve um crescimento importante do que Loureiro chamou de "iniciativa privada" e Novelli destacou como dirigentes "oriundos do sistema financeiro privado".

Olivieri (2007) deu um passo adiante ao sugerir uma explicação para a lógica do processo de nomeação burocrática do Banco Central do Brasil e para a seleção dos seus diretores. Seu estudo reconstruiu o perfil de 13 presidentes e 55 diretores do вСв de 1985 a 2000. Ela dividiu as diretorias da instituição em duas categorias: (i) diretorias de política econômica e (ii) diretorias de fiscalização, normatização e administração. As primeiras seriam responsáveis pela elaboração das políticas com impacto direto sobre a economia e, por isso, estariam ligadas informalmente à própria Presidência da República, que se interessaria pela indicação dos seus ocupantes. As segundas, por sua vez, estariam envolvidas com atividades de fiscalização e normatização bancária, além de assuntos internos e organizacionais do Banco Central. Conforme Olivieri (2007, p. 154), os diretores de política econômica são recrutados majoritariamente fora do Banco, enquanto os diretores de fiscalização vêm, na sua maioria, do corpo funcional do próprio вСв. Assim, Olivieri (2007) permite concluir que о $\mathrm{BCB}$ deve ter critérios diferentes para o preenchimento das suas diferentes diretorias, informação que se perde quando tratamos o corpo de diretores da instituição de maneira agregada (Loureiro 1997; Novelli 2002).

No que se refere ao background educacional, Loureiro (1997) classifica duas escolas muito frequentes no treinamento dos dirigentes do $\mathrm{BC \textrm {B }}$ - a Fundação Getúlio Vargas - isto é, a Escola de Pós-graduação em Economia (EPGE) do Rio de Janeiro - e a PUC-RJ (mais especificamente, seu Departamento de Economia) - como "privatistas" e próximas aos interesses dos bancos privados. Em termos de diferenciação das estratégias profissionais, de acordo com Loureiro (1997), o polo constituído pela EPGE e pela PUC-RJ pode ser denominado 'privatista' sobretudo por tais instituições valorizarem teoricamente a preponderância do papel do mercado no sistema econômico e por estabelecerem laços estreitos com o setor privado, particularmente com bancos, nos quais os egressos dessas instituições atuam como consultores. 
Mais recentemente, Codato et al. (2016) preocuparam-se em identificar não apenas a instituição educacional de origem dos dirigentes, mas o tipo de treinamento aí recebido, se baseado no mainstream econômico ou não. A principal conclusão do estudo é que a origem dos titulares das diretorias ligadas à formulação de política econômica do ВСв é externa, principalmente oriunda do "mercado", e que eles são formados predominantemente em instituições do mainstream econômico. Por outro lado, as diretorias relacionadas com fiscalização, organização do sistema financeiro e administração da própria autarquia são ocupadas por diretores vindos da burocracia do $\mathrm{BCB}$ e formados em instituições fora do mainstream - incluindo-se entre tais diretorias os diretores que não frequentaram cursos propriamente de Economia. É importante salientar que essa distribuição de origens dos diretores ocorre independentemente do partido político que esteja na presidência, PSDB Ou PT.

$\mathrm{O}$ presente artigo inscreve-se nesse elenco de preocupações. $\mathrm{O}$ universo por nós analisado é composto dos quarenta diretores e seis presidentes do ВСв entre os anos de 1995 e $2016^{2}$. Esse período de tempo corresponde a seis mandatos presidenciais distintos no Brasil, assim distribuídos: Fernando Henrique Cardoso, de 1995 a 1998 e de 1999 a 2002, Luiz Inácio Lula da Silva, de 2003 a 2006 e de 2007 a 2010, e Dilma Rousseff, de 2011 a 2014 e de 2015 até a interrupção de seu segundo mandato em razão do golpe de 2016. O nosso objetivo, assim como de grande parte dos trabalhos citados acima, é focar na trajetória ocupacional desses indivíduos, mas com duas importantes diferenças metodológicas ${ }^{3}$.

Em primeiro lugar, a maior parte dos estudos sobre a trajetória ocupacional dos dirigentes dos bancos centrais tende a enfatizar a instituição de origem imediatamente anterior ao recrutamento para o Banco Central. O objetivo deste artigo é ultrapassar essa abordagem, englobando todas as instituições pelas quais os dirigentes do ВСв passaram durante suas vidas profissionais antes de assumirem uma diretoria ou a presidência do Banco. Isso permitirá uma visão mais complexa das trajetórias desses agentes.

Em segundo lugar, em vez de tratarmos essas posições de trajetória separadamente para, depois, identificarmos a frequência de sua recorrência na carreira de diversos indivíduos tomados isoladamente, optamos por utilizar a técnica da análise de redes sociais $(\mathrm{ARS})^{4}$. O nosso objetivo é apresentar, através de quatro sociogramas construí-

2. O número total de indivíduos, porém, é de 45, pois há um nome que se repete: Alexandre Tombini foi diretor do вСв е presidente, tendo sido contado apenas uma vez.

3. A fonte utilizada para as informações foi constituída, principalmente, pelos currículos protocolados no Senado Federal quando da discussão a respeito da aprovação dos pretendentes a diretorias e presidência do Banco Central do Brasil, pois cabe a essa casa aprovar ou não a nomeação para esses cargos. Utilizamos ainda, em alguns poucos casos, jornais e sites pessoais dos ex-dirigentes da instituição.

4. A Análise de Redes Sociais (ARS) é uma metodologia muito utilizada em estudos sobre corporações econômicas (Mintz e Schwartz 1985; Scott 1988; Granovetter 1994), pois permite diagnósticos sobre 
dos com o software NetDraw, as conexões entre os mundos público e privado, entre esses mundos e instituiçôes universitárias, bem como a centralidade de determinadas instituições públicas, empresariais e acadêmicas para a construção das carreiras dos dirigentes do Banco Central do Brasil.

A ARS é frequentemente comparada à fotografia. Nesses casos, entende-se a rede como a captura sincrônica dos elementos de determinada realidade. No entanto, as redes analisadas neste artigo não representam um momento específico, mas sim um período relativamente longo. Mantendo a comparação, a nossa rede representa uma fotografia tirada com o obturador da câmera mantido aberto por um longo período, capturando assim uma quantidade maior de informações. Isso tem consequências para o significado das informações aqui apresentadas, conferindo às nossas redes quatro características importantes. Primeiramente, os atores não compartilham espaços simultaneamente; em segundo lugar, e consequentemente, trata-se de analisar a carreira dos agentes diacronicamente; terceiro, as carreiras são apresentadas como trajetórias individuais que ocorrem dentro de instituições e, por fim, a presença de instituições duradouras permite que diversos indivíduos passem pelas mesmas instituições, criando trajetórias específicas que o nosso texto procura reproduzir. Em suma, as redes por nós analisadas não são nem sincrônicas nem estáticas; ao contrário, representam diacronicamente as trajetórias profissionais dos diretores e presidentes do ВСв e, por isso, conseguem captar o conjunto de conexóes entre pessoas e instituições construído ao longo do tempo.

O artigo está assim estruturado. Além desta apresentação, temos uma primeira parte em que analisamos a estrutura geral da carreira de todos os dirigentes e presidentes do всв (primeiro sociograma). Na segunda parte, concentramos as nossas análises apenas nos presidentes e diretores de política econômica, pois, como já revelamos em outro artigo (Codato et al., 2016), os demais diretores são majoritariamente oriundos do próprio Banco (sociograma 2). Ainda nesta seção, com base nas informações anteriores, identificamos a formação de clusters que nos permitem apontar para a existência de perfis de trajetória e carreira dos dirigentes e presidentes do ВСв (sociograma 3), ficando para a terceira parte a análise de uma clusterização

a estrutura dos grupos econômicos e suas conexões acionárias e diretivas, assim como o poder do sistema financeiro nesse complexo empresarial. No Brasil, a análise de redes ganhou força no final dos anos de 1990 e início dos anos 2000, tendo grande utilidade em estudos sobre as conexões entre o mundo político e organizações sociais (Marques, 1999, 2006; Ansell et al., 2016; Cervi, 2015; Horochovski et al., 2016). Em estudos sobre o Banco Central do Brasil, apenas Olivieri (Olivieri 2007) utilizou essa ferramenta, mas com outro propósito. Redes sociais sistematizam um conjunto de relações (edges) estabelecidas entre determinadas unidades (nodes). ARs é uma perspectiva analítica que tem como grande vantagem incluir na análise as relações entre as unidades observadas e não apenas seus atributos (Wasserman e Faust, 1994, pp.4-6). 
das instituições anteriores de todos os diretores e presidentes (Socriograma 4). Por fim, a título de conclusão, fazemos algumas considerações finais sobre os dados apresentados neste artigo.

De onde vêm os dirigentes e presidentes do $\mathrm{BCB}$ ?

A rede constituída em nossa pesquisa conta com quarenta diretores e seis presidentes do Banco Central do Brasil. Esta rede é caracterizada tecnicamente como uma 2-mode network, pois conjuga dois tipos de unidades de observação (instituições e pessoas), das quais uma constitui as linhas e a outra, as colunas da matriz que dá origem à rede ( Borgatti e Everett, 1997, p. 244). O ganho analítico proporcionado por tal perspectiva é localizar as instituições e os dirigentes no universo de relações que os conecta. Assim, se as nossas unidades de observação são pessoas e instituições, a nossa unidade de análise diz respeito às relações entre elas. Com base nessa rede desenvolvemos sub-redes de tipo 1 -mode, compostas apenas por instituições 5 . O primeiro sociograma, apresentado na Figura 1, sintetiza as instituições pelas quais passaram os dirigentes e presidentes do $\mathrm{BCB}$ е a conexão entre elas ao longo da trajetória ocupacional destes indivíduos.

Essa primeira rede representa a trajetória dos diretores e presidentes do $\mathrm{BCB}$ antes de ocuparem um cargo de comando na autarquia. Na cor vermelha temos os nós constituídos por instituições públicas (incluídas nessa categorização as organizações internacionais, como o Fundo Monetário Internacional, e o próprio $\mathrm{BCB}$ ), em azul as instituições educacionais (universidades, faculdades, escolas, institutos), e, por fim, em amarelo as instituições do setor privado (de diversos setores da economia).

Podemos notar, pelo tamanho do nó, a posição destacada na trajetória dos indivíduos analisados de duas instituições públicas, o próprio $\mathrm{BC}$ в е о Ministério da Fazenda, e de duas instituições de ensino, a Pontifícia Universidade Católica do Rio de Janeiro (PUC-RJ) e a Universidade de São Paulo (USP). A Tabela 1 apresenta as medidas de centralidade do sociograma 1 .

5. Em termos práticos, a matriz é construída da seguinte forma: em uma planilha de Excel registra-se, nas linhas, cada instituição citada na biografia dos dirigentes e presidentes do $\mathrm{BCB}$ e, nas colunas, os nomes destes 45 indivíduos. Nas células da planilha, por meio de “0" (indicando ausência) ou "1" (indicando presença), registramos as conexões entre eles. Isso dá origem a um 2-mode network (que combina unidades de observação distintas, no caso, instituições e indivíduos). De posse dos dados sobre as trajetórias individuais e suas diversas instituições, podemos construir outra matriz em que registramos as conexões apenas entre estas últimas e suas repetições. $\mathrm{O}$ registro das repetições nos permite diferenciar a densidade das conexões por meio da espessura dos vínculos entre as instituições, como se pode ver na Figura 1. Esse procedimento resulta numa 1-mode network (com apenas um tipo de unidade de observação, no caso, instituições). 
FIGURA 1

Rede Social: Trajetória dos Diretores (Todas as Diretorias) e Presidentes do BCB antes de Ocuparem Cargos na Autarquia

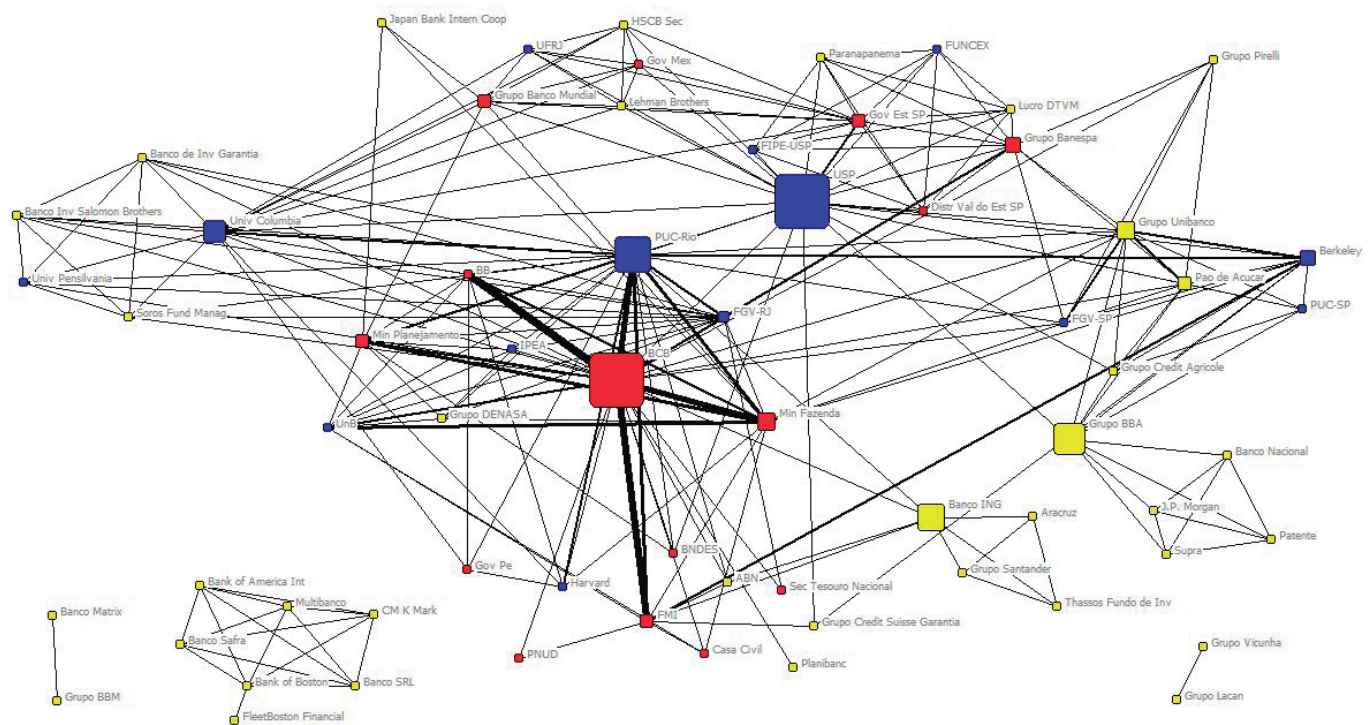

Fonte: elaboração própria.

\section{TABELA 1}

Medidas de Centralidade (Degree e Betweeness) do Sociograma 1

\begin{tabular}{ll}
\hline Degree & Betweenness \\
\hline BCB (45) & USP (376.07) \\
PUC-RJ (35) & BCB (375.68) \\
Ministério da Fazenda (26) & PUC-RJ (221.21) \\
USP (25) & Grupo BBA (196) \\
Univiversity Columbia (18) & Banco ING (150) \\
FMI (17) & Univ. Columbia (119.91) \\
Ministério do Planejamento (16) & Ministério da Fazenda (72,33) \\
FGV-RJ (15) & Grupo Unibanco (67.70) \\
Grupo Unibanco (15) & Berkeley (62,16) \\
BB (14) & Grupo Banespa (54,84)
\end{tabular}

Fonte: Elaboração própria. 
A proeminência visual dessas instituições reflete-se no degree ${ }^{6}$. Nas quatro primeiras posições encontramos estas quatro instituições, com as seguintes medidas de degree (isto é, com maior número de vínculos com outras instituições na rede): $\mathrm{BCB}$ com 45, PUC-RJ com 35, Ministério da Fazenda com 26 e USP com 25.

Entre as dez primeiras posições no que diz respeito ao número de vínculos na rede encontramos ainda duas outras instituições de ensino, a Universidade de Columbia (em quinto lugar, com degree 18) e a Escola de Pós-Graduação da Fundação Getúlio Vargas do Rio de Janeiro (EPGE-FGV) (em oitavo lugar, com degree 15); três instituições públicas, o $\mathrm{FMI}^{7}$ (em sexto lugar, com degree 17), o Ministério do Planejamento (em sétimo lugar, com degree 16) e o Banco do Brasil (em décimo lugar, com degree 14). Uma única instituição é oriunda do setor mercado, a saber, o Grupo Unibanco (em nono lugar, com degree 15). A partir daí, com degrees sempre iguais ou abaixo de 14, temos um misto de instituições governamentais (BNDES, Ipea, governo do Estado de São Paulo), instituições universitárias nacionais e internacionais (PUC-SP, FGV-SP, UFRJ, Universidade da Pensilvânia, Harvard, Berkeley) e um grande número de instituições de mercado, notadamente do mercado financeiro (Salomon Brother, Banco Garantia, HsBC, Banco Safra, Bank of America, entre outras).

As observações acima se confirmam parcialmente pela medida de betweenness ${ }^{8}$. De acordo com esses dados, vemos que USP, BCB e PUC-RJ são as instituições com maior poder de intermediação entre os demais nós, com medidas de betweeness de 376,07; 375,68 e 221,21, respectivamente. A única instituição com alto degree que se encontra fora dessas primeiras quatro posições é o Ministério da Fazenda, com apenas 72,33 de intermediação (em sétimo lugar). Diferentemente da medida de degree, em que o mercado aparecia apenas com uma posição entre as dez primeiras

6. O degree refere-se ao somatório do número de conexões (edges) que determinado elemento (instituição ou indivíduo, representados em nodes) possui. No caso de 2-modes networks, dividimos o degree pelo número total de conexões possíveis para cada nó, obtendo o degree normalizado. O degree normalizado possibilita a comparação dos dados entre instituições e indivíduos, assim como dimensionar percentualmente a integração do nó na rede. Porém, essa normalização só é possível em redes dicotômicas, o que não é o caso das nossas redes 1 -mode (que possui peso nas relações pelo número de diretores compartilhados entre instituições, observado no sociograma pela espessura dos edges). Assim, quando estivermos analisando redes de tipo 1-mode, utilizamos o degree total e quando analisamos redes de tipo 2-mode, utilizamos a medida do degree normalizado (Wasserman e Faust, 1994, p. 179).

7. Apesar do FMI ser uma instituição internacional de caráter multilateral, classificamo-la aqui como pública, pois a separação entre público e instituições internacionais dissiparia demais nossa categorização.

8. Betweenness (intermediação) é uma medida de centralidade que identifica quais são os nós mais importantes na intermediação entre o conjunto dos nós da rede. Segundo Wasserman e Faust, as unidades com maior grau de betweeness são potencialmente aquelas que têm maior controle sobre as interações entre os nós (1994, p.188). Em resumo, um nó com alto betweeness é aquele que se constitui em ponto de passagem necessário para que os demais nós possam se conectar. Constitui-se, assim, em um gatekeeper ou broker. 
(com o Grupo Unibanco), este setor agora ocupa três das dez primeiras posições, com о Grupo BвA, com betweeness de 196 (quarta posição), Banco ING, com betweeness de 150 (em quinto lugar) e o Grupo Unibanco, com betweeness de 67,70 (oitava posição). ${ }^{9}$ Duas instituições de ensino estão presentes entre as dez primeiras posições: Universidade de Columbia, com betweeness de 119,91 (sexta posição), e Berkeley, com 62,16 de betweeness (nona posição).

Portanto, se levarmos em consideração as dez primeiras posições nas medidas de degree e de betweeness, os três setores parecem ter importância na trajetória dos dirigentes e presidentes do Banco Central. Tal resultado é esperado. Afinal, dada a natureza da instituição - uma burocracia insulada e tecnicamente competente, cuja função é lidar com temas complexos de política econômica e, em particular, de política monetária -, parece haver uma proximidade funcional entre ela e os três setores aqui analisados. É plausível supor que um "bom gestor" do вСв precise ter carreira pública, passar pelas principais escolas de formação em economia e possuir intimidade com a dinâmica do mercado. Nesse sentido, a natureza da instituição ajudaria a entender a presença destacada na rede do próprio BC, o predomínio de USP e PUC-RJ como instituições de ensino e de instituições vinculadas ao sistema financeiro privado ${ }^{10}$. A medida de betweenness, inclusive, pode indicar quais são as instituições que servem de "ponto de encontro", isto é, onde os diretores do Banco Central se conhecem e fazem networking.

No entanto, embora todas essas instituições sejam importantes tanto pela quantidade de conexões que possuem (degree) como pela sua capacidade de intermediar relações entre os demais nós da rede (betweeness), fica bastante evidente que instituições de ensino (USP e PUC-RJ) e o próprio Banco Central se destacam na trajetória dos dirigentes e presidentes desta última instituição. As instituições de mercado, de acordo com a rede acima, têm baixo número de vínculos com os demais nós da rede, ainda que apareçam melhor posicionadas quando se trata do lugar que ocupam no seu interior. Porém, tanto num caso como no outro, estão sempre bem abaixo das instituições oriundas dos outros dois setores (público e ensino). Acreditamos que isso se deve ao fato de a rede que acabamos de analisar abranger todas as diretorias dо вСв (as que formulam política econômica e as que têm funções administrativas). Os dados podem ser diferentes se levarmos em conta apenas as diretorias de política econômica. Vejamos esse ponto a seguir.

9. O Grupo Banespa encontra-se entre as dez primeiras instituições, com 58,84 de betweeness (décima posição). Entretanto, os diretores analisados passaram por esse banco antes da privatização, portanto o consideramos pertencente ao setor público (tal como o Banco do Brasil).

10. Observe-se, quanto a este ponto, a posição de pouca importância na rede, tanto quanto ao degree como ao betweeness, dos bancos públicos (BNDES е BB). 
De onde vêm os diretores de política econômica?

Seguindo o modelo proposto por Olivieri (2007), vamos separar as diretorias do Banco Central em dois tipos - diretorias encarregadas de regulação bancária e diretorias dedicadas à formulação de política econômica - e gerar o sociograma correspondente (Figura2). As diretorias que manipulam os instrumentos que afetam a política econômica dos governos brasileiros são as seguintes: Diretoria de Política Econômica, Diretoria de Política Monetária e de Assuntos Internacionais e Diretoria de Gestão de Riscos Corporativos.

FIGURA 2

Rede Social: Trajetória dos Diretores e Presidentes do ВСВ antes de Ocuparem Cargos na Autarquia (Diretorias de Política Econômica)

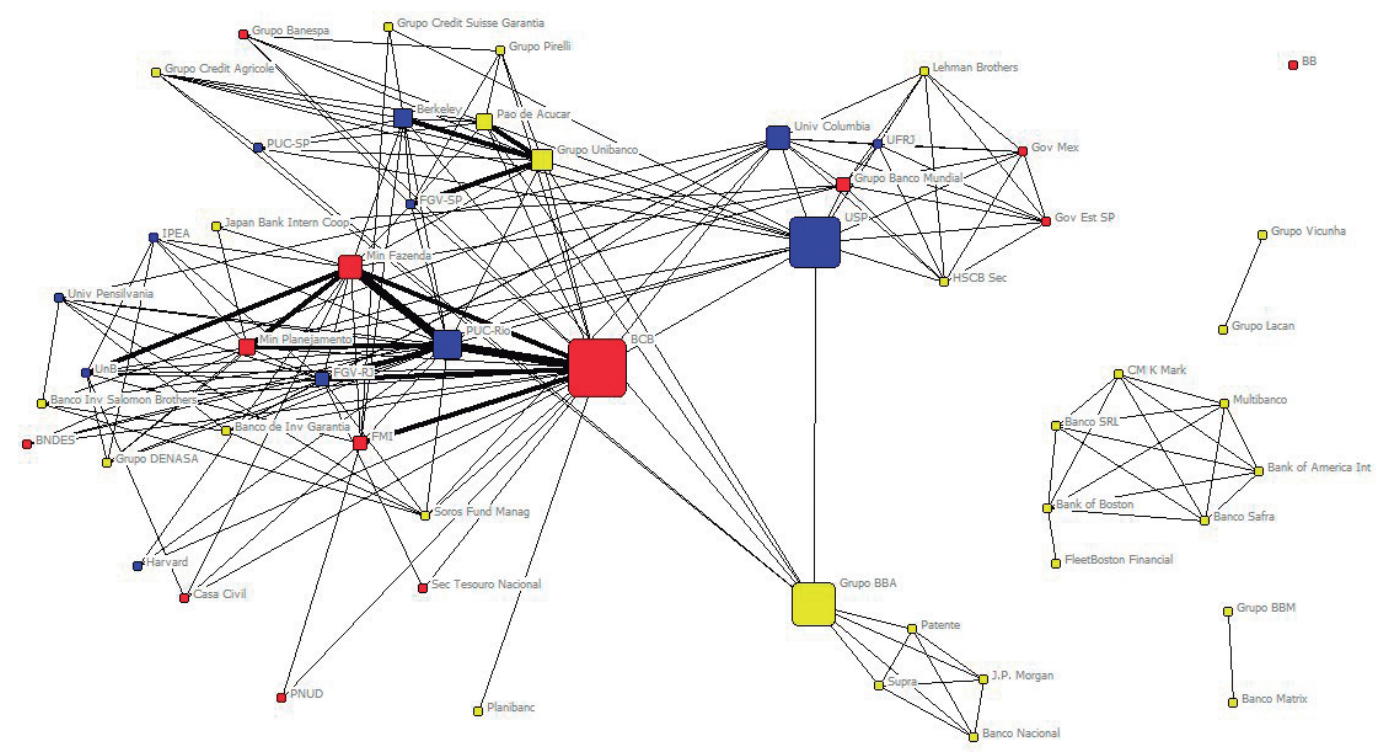

Fonte: elaboração própria.

Iniciando pela observação estritamente visual, podemos perceber que não há grande diferença nesta rede quando comparada àquela que inclui todas as diretorias dо всв. Vejamos, de maneira mais precisa, como isso se reflete nas medidas de degree e betweeness, apresentadas na Tabela 2. 
TABELA 2

Medidas de Centralidade (Degree e Betweeness) do Sociograma 2

\begin{tabular}{ll}
\hline Degree & Betweenness \\
\hline BCB (28) & BCB $(217,64)$ \\
PUC-RJ (25) & USP $(188,35)$ \\
Ministério da Fazenda (20) & Grupo BBA (148) \\
USP (18) & PUC-RJ (89,79) \\
FGV-RJ (15) & Univercity Columbia (65,82) \\
Grupo Unibanco (15) & Ministério da Fazenda (65,29) \\
University Columbia (14) & Grupo Unibanco (57,40) \\
Ministério do Planejamento (13) & Berkeley (47,93) \\
Berkeley (12) & Pão de Açúcar (31,40) \\
Pão de Açúcar (11) & Ministério do Planejamento (24,40) \\
\hline
\end{tabular}

Fonte: Elaboração própria.

A Tabela 2 reitera a percepção visual. As diferenças entre as trajetórias dos diretores de política econômica em relação aos diretores, tomados no seu conjunto, são muito pequenas e não significativas quando comparadas com a Tabela 1. Tanto no que diz respeito à quantidade de vínculos dentro da rede (degree) quanto à posição de intermediação (betweeness), ВCB ( 45 e 375, 68), PUC-RJ (35 e 221,21) e USP (25 e 376,07$)$ se destacam novamente, apenas com alterações de ordem. Assim, о в вв continua sendo uma instituição central no recrutamento dos seus próprios diretores, junto com outras três instituições do setor público: o Ministério da Fazenda e o Ministério do Planejamento.

Os dados da Tabela 1 e 2 nos obrigam a fazer uma consideração especial sobre as instituições de ensino. Nas duas tabelas vemos que PUC-RJ e USP são as instituições de formação centrais dos nossos diretores . No entanto, vale observar que, no que concerne ao número de vínculos dentro da rede, nas duas tabelas, das dez posições, cinco são ocupadas por universidades (PUC-RJ, USP, FGV-RJ, Columbia e Berkeley). No que se refere à capacidade de intermediação com outras instituições, apenas a FGV$-\mathrm{RJ}$ fica de fora. Isso mostra o lugar central dessas instituições na carreira dos nossos dirigentes e não seria exagero supor que se constituem em passagens obrigatórias para ter acesso às demais instituições da rede e às posições de comando dentro do вСв. Nesse sentido, um estudo qualitativo do ensino de economia professado por essas universidades impõe-se como essencial na análise da formação das preferências dos atores em questões de política econômica. 
As instituições de mercado, por sua vez, continuam a ocupar posições claramente subalternas entre as dez primeiras posições de degree, em que encontramos apenas o Grupo Unibanco. Sua posição melhora no que concerne à capacidade de intermediar o contato com outras instituições ao longo da carreira, com o Grupo BBA, mais uma vez, assumindo posição de destaque.

Os dados apresentados até o momento, por um lado, contestam os achados de Codato et al. (2016) e, por outro, reafirmam-nos. Quando tomamos toda a carreira dos diretores e presidentes do $\mathrm{BCB}$, e não apenas a sua última posição antes de ocupar o cargo, a vinculação exclusiva com qualquer um dos setores (público, ensino ou mercado) se desfaz. Para sermos mais enfáticos, os achados de Codato et al. (2016), que apontavam para uma clara distinção entre diretores administrativos (oriundos do interior do próprio $\mathrm{BCB}$ ) e diretores de política econômica (oriundos do mercado) devem ser nuançados quando tomamos a visão de conjunto da carreira desses indivíduos. No caso dos diretores de política econômica analisados aqui, os dados mostram que não há clara vinculação com o mercado, cabendo também às instituições públicas e de ensino um lugar de destaque na rede que constitui a carreira desses agentes. Por outro lado, a afirmação de que os diretores de política econômica tendem a ser originários de instituições de ensino caracterizadas como pertencendo ao mainstrean econômico ${ }^{11}$ parece ser reforçada. Essa afirmação ganha força se fizermos uma análise dos clusters que se formam no interior da rede (sociograma apresentado na Figura 3).

Por meio da "clusterização" da rede conseguimos identificar estruturas comunitárias que representam trajetórias típicas das carreiras que levam às diretorias de política econômica no $\mathrm{BCB}^{12}$. $\mathrm{O}$ sociograma exposto na Figura 3 revela alguns pontos interessantes e esclarece um pouco mais os dados apresentados com base nas medidas de centralidade.

Inicialmente, levando-se em consideração os tamanhos dos nós na rede, podemos identificar quatro grandes clusters nas conexões que compõem as carreiras dos diretores de política econômica: o cluster em torno do $\mathrm{BCB}$, o cluster em torno da UsP, o cluster em torno do Grupo Unibanco e o cluster do "mercado puro".

11. "O mainstream econômico são as teorias e técnicas de pesquisa ensinadas nas universidades mais prestigiosas, cujos resultados são publicados nos melhores periódicos da área e que recebem financiamento das principais agências de fomento. A ênfase na formalização matemática é um traço comum a todo o mainstream econômico (são raras as teorias do mainstream que não são matematicamente formais). Para a elite da profissão, 'se não for passível de modelagem, não é economia'” (Dequech, 2007, p. 702). Para essa discussão, ver Colander et al., 2004; Dequech, 2007 e Codato et al., 2016.

12. A ferramenta usada para identificar esses agrupamentos é o algoritmo chamado "Girvan-Newman". Tal algoritmo identifica "estruturas comunitárias” (Girvan e Newman 2002, p.1) através da remoção das conexões com maior betweenness (Girvan e Newman, 2002, p.3). Essa remoção gera uma separação dentro da rede e cada uma das partes passa a ser caracterizada como um agrupamento (cluster). 
FIGURA 3

Rede Social: Trajetória dos Presidentes e Diretores (Diretorias de Politica Econômica) do BCB antes de Ocuparem Cargos na Autarquia, com Clusterização pelo Método de Girvan-Newmann

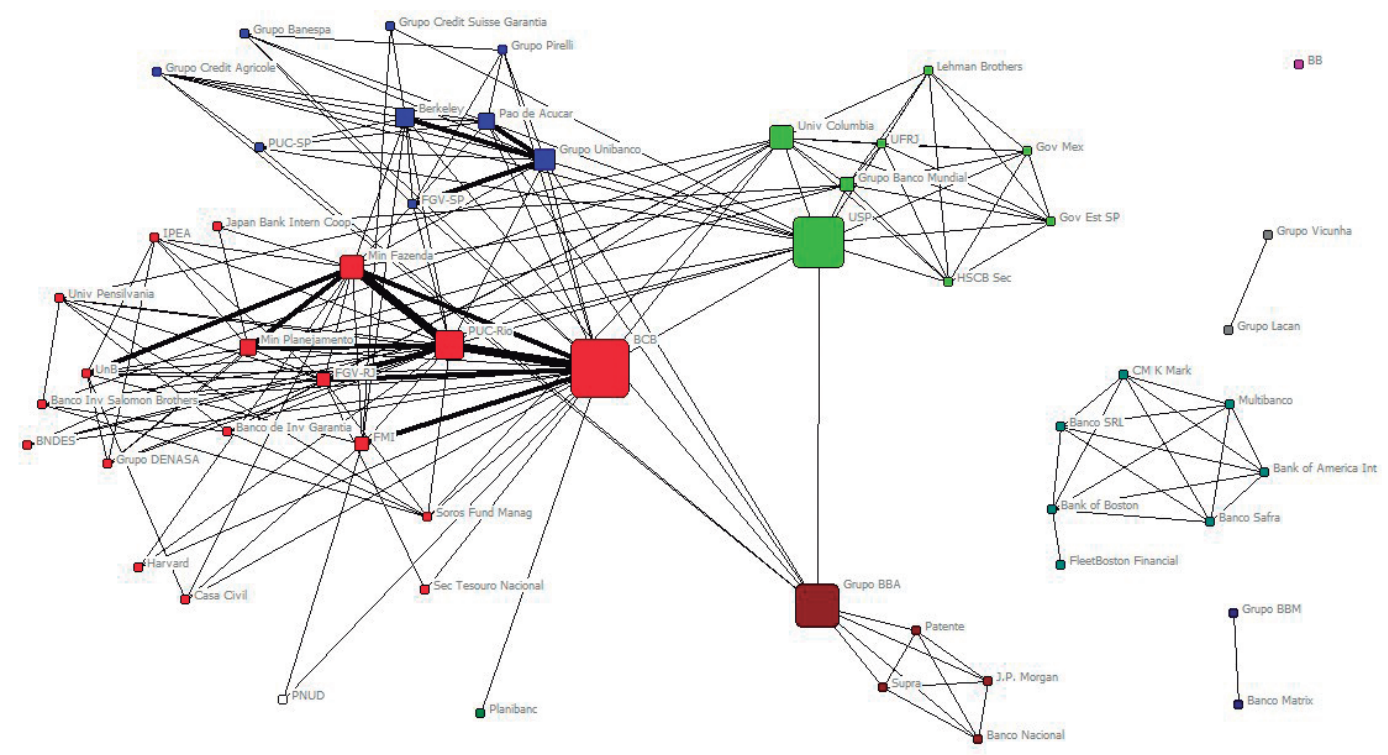

Fonte: elaboração própria.

O cluster em torno do $\mathrm{BCB}$ tem no seu núcleo uma intensa conexão entre três instituições públicas (о ВСв, o Ministério da Fazenda e o Ministério do Planejamento) e duas instituições de ensino fortemente vinculadas ao mainstrean econômico. A espessura dos laços que conectam essas instituições revela uma intensa circulação dos diretores de política econômica por elas, antes de chegar aos seus cargos no ВСв. A importância da PUC-RJ é particularmente significativa, pois ela está fortemente conectada às três instituições públicas, ao passo que a FGV-RJ se relaciona mais fortemente com о ВСB e com a própria PUC-RJ. Portanto, como dissemos acima, o lugar central no recrutamento dos dirigentes de política econômica das instituições de ensino em que predomina uma formação de economia baseada no mainstrean dessa disciplina, tal como dito por Codato et al. (2016), é confirmado pelo sociograma apresentado na Figura 3. Observe-se ainda que a periferia desse cluster é muito mais diversificada, contando com instituições públicas, de ensino e de mercado, mas com posição muito mais marginal no processo de recrutamento, exceto, talvez, pela forte relação entre UnB e o Ministério da Fazenda. Ou seja, nesse cluster, o mercado se faz presente, mas nenhuma instituição desse setor parece concentrar a trajetória dos agentes.

O cluster em torno da USP explica a presença sistemática dessa instituição de ensino nas primeiras posições das medidas de centralidade. Ele revela um misto de 
instituições de ensino (Universidade de Columbia e UFRJ, além da própria USP), de governo (governos de São Paulo, Banco Mundial e do México) e de mercado (Lehman Brothers, HSBC). Observe-se, porém, que os traços que estabelecem as conexões nem de longe são tão expressivos quanto os que conectam as instituições centrais do primeiro cluster.

O cluster em torno do Grupo Unibanco realiza uma mistura mais homogênea, pois ali encontramos apenas instituições de ensino, a saber, a FGV-SP, a PUC-SP e Berkeley, sendo estas duas últimas as mais intensamente conectadas com os dois grandes grupos econômicos deste cluster, Pão de Açúcar e Grupo Unibanco.

Por fim o cluster totalmente homogêneo do mercado. Na verdade, os grupos do mercado aparecem como quatro grupos separados, situados à direita do sociograma. O único que se conecta com o corpo maior da rede é o Grupo BBA, prioritariamente com instituições do setor privado, e com laços muito tênues com as instituições públicas. Do ponto de vista das medidas de centralidade, como vimos, apenas o Grupo BBA se destaca, sendo as demais instituições bastante insignificantes nesse sentido.

Resumindo, no que diz respeito exclusivamente aos diretores de política econômica, os clusters acima revelam duas coisas importantes. De um lado, algumas instituições públicas e de ensino parecem funcionar como magnetes com alto poder de atração na carreira de muitos dos agentes por nós analisados. É intensa a circulação dos dirigentes por essas instituições, o que se expressa, como vimos, nas medidas de centralidade e, visualmente, na espessura dos traços. Por outro lado, no que diz respeito às instituições de mercado, as medidas de centralidade e a clusterização mostram que, apesar da importância de alguns grupos (como o BBA e o Unibanco), este setor tem uma presença significativa do ponto de vista quantitativo, mas mais fragmentada. Diferentemente dos setores públicos e de ensino (sobretudo о ВСв е a PUC-RJ), não há no mercado instituições com alto poder de atração. Isso, evidentemente, não quer dizer que o mercado não seja importante na trajetória dos atores aqui analisados. A presença numericamente significativa de instituições oriundas desse setor revela que o treinamento no mercado (especialmente em instituições do setor financeiro privado) é importante para o recrutamento dos diretores de política econômica do BC. Assim, se os nossos dados estão corretos, uma eventual coincidência entre as políticas econômicas implementadas pelos diretores do $\mathrm{BCB}$ e os interesses do capital financeiro deveria ser explicada tanto por uma teoria da captura (ou da influência, para usar a expressão de Offe e Ronge, 1984) como pela homologia entre as "ideias econômicas"13 desses agentes e os interesses da banca.

13. Uma ampla e recente literatura tem discutido, teórica e metodologicamente, questões referentes ao impacto das ideias na formulação das políticas públicas e sua autonomia em relação aos interesses "ob- 
FIGURA 4

Rede Social: Trajetória dos Presidentes e Diretores do BCB antes de Ocuparem Cargos na Autarquia, com Clusterização pelo Método de Girvan-Newmann

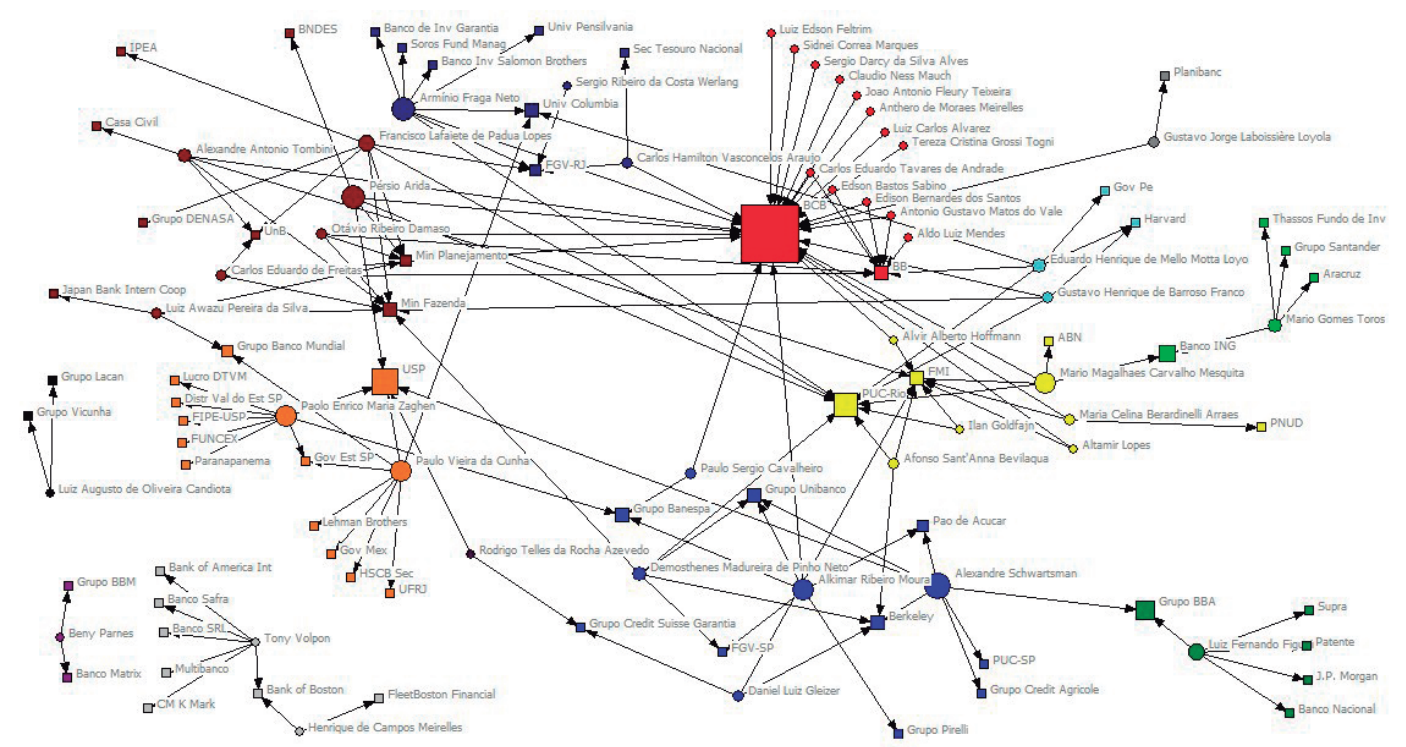

Fonte: elaboração própria.

As trajetórias típicas

Apresentamos acima uma visão de conjunto da carreira dos dirigentes e presidentes do $\mathrm{BCB}$, ocultando os indivíduos e apresentando apenas as instituições, mesmo quando limitamos nossa análise aos diretores de política econômica. A seguir, por meio de uma 2-mode network, que combina os indivíduos e as instituições, tentaremos captar alguns agrupamentos que nos revelem tipos de trajetórias profissionais de todos os dirigentes dо всв. Isso pode ser visto no sociograma apresentado na Figura 4.

O sociograma exposto na Figura 4 revela treze tipos de trajetória que caracterizam a carreira dos dirigentes e presidentes do $\mathrm{BCB}$ no período analisado. A nosso ver, é possível reduzir esses trezes tipos a alguns padrões mais gerais. Antes de tudo convém observar que apenas quatro dos treze clusters concentram 68\% dos indivíduos por nós pesquisados: o cluster vermelho, com 13 indivíduos (29\%), e os clusters azul anil, amarelo e marrom, cada um com seis indivíduos (39\%).

Os clusters vermelho e marrom são muito interessantes porque, em ambos, predomina claramente uma trajetória em instituições públicas. No cluster ver-

jetivos", mesmo aqueles beneficiados diretamente por tais políticas. Sobre este ponto ver (Hall, 1989; Blyth, 2002; Goldstein e Keohane, 1993; Béland, 2010; Schmidt, 2010; Sikkink, 1991), entre outros. 
melho, que tem о вСв como centro, não se trata de predomínio, mas de domínio absoluto do setor público na determinação da trajetória de carreira dos agentes, muito provavelmente concentrada nos indivíduos das diretorias administrativas da autarquia. No marrom, a UnB, o Japan Bank (por meio de Luiz Awazu) e o grupo Denasa (através de Francisco Lopes) são exceções num emaranhado de instituições públicas (Casa Civil, Ministério da Fazenda, Ministério do Planejamento, Ipea, BNDES). Essa mistura garante ao cluster a presença de funcionários com carreiras predominantemente públicas, inclusive dentro do próprio $\mathrm{B} \mathrm{CB}$ (соmo Alexandre Tombini), de indivíduos que trafegam por diversas instituições públicas, além do ВСв (como Pérsio Arida), e daqueles que transitam entre o mercado e instituições públicas (como Luiz Awazu e Francisco Lopes).

Entre os grupos com mais indivíduos, o cluster azul pode ser chamado de o "cluster paulista”, um misto de instituições de ensino (FGV-SP, PUC-SP e Berkeley) e grupos econômicos sediados preferencialmente neste estado da federação, como os grupos Banespa, Unibanco e Pão de Açúcar. A proximidade com o mercado se dá em parte pela via do sistema financeiro (com os grupos Banespa e Unibanco, já citados, mas também com o Crédit Suisse, o Crédit Agricole e o Grupo Pirelli, este último por meio de suas instituições financeiras), em parte por setores do capital comercial (Pão de Açúcar).

Por fim, entre os maiores clusters, o amarelo evidencia o poder de atração da PUC-RJ, revelado ao longo de todo o nosso artigo. Nele vemos essa instituição de ensino rodeada, quase sozinha, por um conjunto de nomes. Os indivíduos desse cluster parecem trafegar entre PUC-RJ e FMI, preferencialmente, antes de chegar a um cargo de direção no вСв.

O que nos dizem os restantes $32 \%$ de indivíduos presentes na rede? Basicamente duas coisas. De um lado, temos dois clusters, o azul escuro e o alaranjado (sobretudo este último), que de forma bem acentuada apresentam uma mistura de instituições públicas (Secretaria do Tesouro Nacional, Governo do México, Governo de São Paulo), mercado e instituições de ensino (USP, UFRJ, FIPE-USP, Universidade de Columbia, Universidade da Pensilvânia e FGV-RJ). Chama a atenção que o contato desse grupo com o mercado se dê majoritariamente (e especialmente no grupo azul escuro) com o sistema financeiro privado. Esses dois grupos, porém, contam com apenas dois indivíduos - Paolo Zaghen e Paulo Cunha -, no caso do grupo alaranjado, e três indivíduos - Armínio Fraga, Carlos Araújo e Sérgio Werlang -, no caso do grupo azul escuro. Um outro cluster é o azul piscina, com apenas dois indivíduos e formado por uma instituição pública (o governo de Pernambuco) e uma instituição de ensino (Harvard), cujo membro mais famoso é Gustavo Franco.

Os demais clusters, todos juntos, contam com sete indivíduos (15,5\%). Aqui 
temos o grupo do "mercado puro". Os indivíduos aí presentes quase não passam nem por instituições públicas nem por instituições de ensino (a exceção é Gustavo Loyola e sua conexão com о вСв). Suas carreiras e treinamentos se dão inteiramente no universo do mercado, quase que integralmente no sistema financeiro privado, em instituições bancárias muito diversificadas. A rede clusterizada mostra, portanto, que, diferentemente do setor público e do setor ensino, em que algumas poucas instituições se constituem em polos estruturantes da carreira, no setor mercado a pulverização das instituições impede que qualquer uma delas exerça o mesmo papel. No entanto, a rede também mostra que se, por um lado, nenhuma instituição financeira funciona como magnete, por outro, o sistema financeiro privado como um todo é um locus central de recrutamento dos dirigentes do всв. Obviamente, essa afirmação se fortalece se ao grupo do "mercado puro" somarmos aquelas instituições financeiras que compõem os demais clusters.

Antes de passarmos às conclusões, convém fazer duas últimas observações. Primeiramente, que os clusters que compõem a rede estão, na sua grande maioria, conectados entre si e, portanto, há indivíduos e instituições que, apesar de terem sido alocadas num cluster, conectam-se a outros indivíduos e instituições em outros clusters (temos apenas três pequenos subgrafos desconectados do grafo principal). $\mathrm{O}$ que descrevemos acima são trajetórias típicas. Assim, por exemplo, quando falamos do cluster do "mercado puro", estamos desconsiderando essas conexôes externas a que alguns indivíduos desse cluster poderiam acessar. Em segundo lugar, há alguns poucos clusters que efetivamente não se conectam à grande rede. Estão situados no lado esquerdo do sociograma e compõem, por assim dizer, o "viveiro" de dirigentes cuja carreira prévia se dá exclusivamente no mercado financeiro.

\section{Conclusões}

Usando medidas de centralidade (degree e betweeness) e técnicas de clusterização permitidas pela análise de redes sociais, o estudo da carreira dos dirigentes do Banco Central do Brasil (diretores e presidentes) nos permite três conclusões.

A primeira delas é que há ganhos analíticos importantes quando olhamos para toda a carreira prévia dos dirigentes do Banco Central a fim de entender a sua lógica de recrutamento. Um olhar exclusivo para a última posição ocupacional antes de assumir a função de diretor ou presidente do Banco resultava em conclusões enviesadas, sobretudo para os dirigentes das diretorias de política econômica, que tenderiam a aparecer como oriundos exclusivamente do mercado, mas também para os dirigentes de diretorias administrativas, que surgiam como funcionários públicos apenas. A análise de redes torna o resultado mais complexo. Revela que, sim, de fato, 
há carreiras que ocorrem exclusivamente no sistema financeiro e no setor público, mas a maior parte delas é mista.

A segunda conclusão é o papel central que instituições de ensino desempenham na construção da trajetória profissional dos dirigentes. As mais importantes são UsP, FGV-RJ e, principalmente, PUC-RJ. São, como observamos, instituições em que se propaga o mainstream econômico e tendem a ser um local preferencial de passagem, principalmente para aqueles que atuam nas direções de política econômica. Isso, a nosso ver, abre um importante campo de pesquisa acerca do conteúdo substantivo do ensino ministrado nessas instituições. Sociologicamente falando, esse nos parece ser o locus preferencial de produção dos esquemas informacionais que orientam os dirigentes do Banco Central em questões de política econômica e, por essa razão, o lugar das instituições universitárias no sistema de poder em questão não deve ser menosprezado. Ademais, é importante lembrar que os dirigentes do BCB se transformam, eles próprios, em professores, com muita frequência nas mesmas instituições que os formaram. Desse modo, não são apenas receptores dos esquemas informacionais aí produzidos, mas também seus propagadores.

A terceira conclusão, mais especulativa, diz respeito à homologia entre as carreiras aqui analisadas e a natureza da própria instituição que estudamos. O Banco Central é uma instituição do Estado brasileiro, estruturada segundo os critérios típicos da burocracia moderna. Ao mesmo tempo, é uma instituição com uma função manifesta evidente, isto é, produzir política monetária a fim de cuidar da preservação do valor da moeda nacional. Nesse sentido, trata-se de instituição com evidente conexão funcional com o mercado e, em especial, com aqueles que operam no setor financeiro.

Desse modo, fica difícil não analisar as três dimensões da carreira prévia dos dirigentes - o mercado, o público e o ensino - como efeitos da posição objetiva do próprio Banco no sistema de instituições do Estado brasileiro. Como parte deste Estado, o Banco tem que se constituir como organização pública, criar quadros administrativos e, por conseguinte, viabilizar carreiras internas até o topo. Como gestor da política monetária não pode virar as costas para o mercado e para os agentes que obtêm o complexo conhecimento técnico de gestão monetária on the job ou para aqueles que obtêm tal conhecimento em instituições de ensino de economia que privilegiam técnicas adequadas à sua função.

Reiteramos, assim, o que dissemos anteriormente. Se há alguma coincidência entre os interesses do mercado financeiro e a política econômica implementada pelo banco (e somente uma análise longitudinal dos efeitos sistemáticos dessa política poderia confirmar tal assertiva), é certamente plausível pesquisar as origens dessa eventual coincidência nas íntimas conexões da instituição com o mercado. No entanto, parece que tal conexão não é condição necessária para que isso possa ocorrer. A formação 
acadêmica dos que aí chegam, partindo de um campo universitário amplamente dominado pelo mainstream econômico, pode induzir о $\mathrm{BC}$ В a atuar num determinado sentido em função da orientação intelectual e cognitiva de seus diretores, ainda que, como instituição, não seja diretamente instrumentalizado por nenhum grupo de interesse específico, como as instituições privadas do setor financeiro, por exemplo. Dito de outro modo, o problema da "independência" do Banco Central não pode ser reduzido a uma problemática estritamente formalista (existência ou não de uma legislação que garanta sua autonomia), mas deve ser pensado também tomando-se por base o lugar desta instituição no sistema de poder e de suas conexões perenes com outras instituições do sistema social, das quais ele recruta preferencialmente os seus dirigentes.

\section{Referências Bibliográficas}

Adolph, Christopher. (2013), Bankers, bureaucrates, and Central Bank politics: the myth of neutrality. Nova York, Cambridge University Press.

AnSELl, Christopher et. al. (2016), "Who says networks, says oligarchy? Oligarchies as 'rich club’ networks”. Connections, 35 (2): 20-32.

BÉLAnd, Daniel. (2010), “The idea of power and the role of ideas". Political Studies Review, 8: 145-154.

BLYTH, Mark. (2002), Great transformations: economic ideas and institutional change in the Twentieth Century. Cambridge, Cambridge University Press.

Borgatti, S. P. \& Everett, M. G. (1997), "Network analysis of 2-mode data”. Social Networks, 19 (3): 243-269.

Cervi, Emerson. (2015), "Análise de elites em perspectiva relacional: a operacionalização da análise de redes sociais (ARs)”. In: Perissinotto, R. \& Codato, A. (orgs.). Como estudar elites. Curitiba, Editora da UFPR, pp. 95-118.

Codato, Adriano et al. (2016), "Mainstream econômico e poder: uma análise do perfil dos diretores do Banco Central do Brasil nos governos do PSDB e do PT". Nova Economia, 26 (3): 687-720.

Colander, D. et al. (2004), “The changing face of mainstream economics”. Review of Political Economy, 16 (4): 485-499.

Cunierman, Alex. (1992), Central Bank strategy, credibility, and independence: theory and evidence. Cambridge, The Mit Press.

Dequech, David. (2007). "Neoclassical, mainstream, orthodox, and heterodox economics". Journal of Post Keynesian Economics, 30 (2): 279-302.

FARVAQUe, Etienne et al. (2009), “Select your committee: the impact of Central Bankers' background on inflation". Economie Internationale, (117): 99-129. 
Girvan, M. \& Newman, M. E. (2002). "Community structure in social and biological networks". Proc. Natl. Acad. Sci. 99 (12): 7821-7826.

Göhlmann, Silja \& VAubel, Roland. (2007), “The educational and occupational background of central bankers and its effect on inflation: an empirical analysis". European Economic Review, 51 (4): 925-941. Disponível em http://linkinghub.elsevier.com/retrieve/pii/ S0014292106000675, consultado em 14 jan., 2015.

Goldstein, Judith \& KeOhane, R. O. (1993), "Ideas and foreign policy: an analytical framework". In: Goldstein, J. \& KeOHANe, R. O. (orgs.). Ideas and foreign policy: beliefs, institutions and political change. Ithaca, Cornell University Press, pp. 3-30.

Granovetter, M. (1994), “Business Group.” In: Smelser, N. J. \& Swedeberg, R. The handbook of economic sociology. Princeton, Princeton University Press, pp. 453-475.

Hall, Peter (org.). (1989), The political power of economic ideas: keynesianism across nation. Princeton, Princeton University Press.

Horochovski, Rodrigo et al. (2016), "Estruturas de poder nas redes de financiamento político nas eleições de 2010 no Brasil”. Opinião Pública, 22 (1): 28-55.

Lebaron, Frédéric. (2010), "European Central Bank leaders in the global space of Central Bankers: a geometric data analysis approach”. French Politics, 8 (3): 294-320.

Loureiro, M. R. (1997), "Gestão econômica e democracia: uma perspectiva comparada”. In: . Os economistas no governo: gestão econômica e democracia. Rio de Janeiro, Editora Fundação Getulio Vargas, pp. 119-173.

Marques, E. C. (1999), "Redes sociais e instituições na construção do Estado e da sua permeabilidade". Revista Brasileira de Ciências Sociais, 14 (41): 45-67. . (2006), "Redes sociais e poder no Estado brasileiro: aprendizados a partir de políticas urbanas". Revista Brasileira de Ciências Sociais, 21 (60): 15-41.

Mintz, B. \& Schwartz, M. (1985). The power structure of Americam business. Chicago, University of Chicago.

Novelli, J. M. N. (2002), Instituições, política e ideias econômicas: o caso do Banco Central do Brasil (1965-1998). São Paulo, Annablume.

Offe, Claus \& Ronge, Volker. (1984), “Teses sobre a fundamentação do conceito de 'Estado capitalista' e sobre a pesquisa política de orientação materialista”. In: OfFE, Claus (org.). Problemas estruturais do Estado capitalista. Rio de Janeiro, Tempo Brasileiro.

Olivieri, Cecília. (2007), "Política, burocracia e redes sociais: as nomeações para o alto escalão do Banco Central do Brasil”. Revista de Sociologia e Politica, (29): 147-168. Disponível em http://www.scielo.br/scielo.php?script=sci_arttext\&pid=S0104-44782007000200011\&ln $\mathrm{g}=\mathrm{pt} \& \mathrm{nrm}=\mathrm{iso} \& \mathrm{t} \operatorname{lng}=\mathrm{pt}$.

Schmidt, V. A. (2010), “Taking ideas and discourse seriously: explaining change through discursive institutionalism as the fourth 'new institutionalism'". European Political Science Review, 2 (1): 1-25. 
Scoтt, J. (1988). "Social network analysis and intercorporate relations”. Hitotsubashi Journal of Commerce and Management, 1 (23): 53-68.

SikкInk, Kathryn. (1991), Ideas and institutions: developmentalism in Brazil and Argentina. Ithaca, Cornell University Press.

WAsSERMAN, S. \& FAUST, K. (1994). Social network analysis: methods and applications. Cambridge, Cambridge University Press.

\section{Resumo}

Redes sociais e recrutamento: o caso dos diretores e presidentes do Banco Central do Brasil (1994-2016)

Este artigo analisa a trajetória profissional de 45 dirigentes do Banco Central do Brasil (diretores e presidentes). O objetivo é captar a estrutura da carreira desses agentes, levando-se em consideração todos os cargos ocupados e a conexão entre eles. Para tanto, usamos a metodologia da Análise de Redes Sociais (ARS), em particular as suas medidas de centralidade (degree e betweeness) e suas técnicas de clusterização. As fontes utilizadas foram as biografias disponíveis na página da instituição, os currículos submetidos à aprovação do Senado Federal, o website da Bloomberg e o sistema Bloomberg Professional, além do Dicionário Histórico Biográfico Brasileiro do CPDoc. Nossas conclusões apontam para a complexidade das carreiras desses agentes, que combinam os setores público, privado e de ensino.

Palavras-chave: Banco Central; Redes sociais; Carreira; Dirigentes; Presidentes. 


\section{Abstract}

Social networks and the recruitment of directorates and presidents of the Central Bank of Brazil (1994-2016)

The article analyses the professional career of 45 chairs of Brazilian Central Bank (directorates and presidents). Its purpose is to capture the career structure of these agents, taking into consideration every position throughout their career and the connections among them. Therefore, we use Social Network Analysis, especially its centrality measures (degree and betweeness), and its clustering techniques. The sources consulted were biographies available on the Central Bank's website, the curricula used by the Federal Senate to approve the directors, the Bloomberg's website, the Bloomberg Professional System, and the Dicionário Histórico Biográfico Brasileiro elaborated by CPDOC. We conclude that the Central Bank's directorates and presidents have very complex careers, which combine positions in the public, private and university sectors.

Keywords: Central Bank; Social network; Career; Directorates; Presidents.

Texto recebido em 30/1/2017 e aprovado em 29/5/2017. DoI: 10.11606/0103-2070. ts.2017.125881.

RENATO MONSEFF PERISSINOTTo é professor do Departamento de Ciência Política da Universidade Federal do Paraná (UFPR) e pesquisador do CNPq. E-mail: monseff@gmail.com.

MARCO ANTONIO RIBAS CAVALIERI é professor do Departamento de Economia da Universidade Federal do Paraná (UFPR).E-mail: cavaga@uol.com.br.

ERIC GIL DANTAS é doutorando do Programa de Pós-graduação em Ciência Política da Universidade Federal do Paraná (UFPR).E-mail: ericgildantas@gmail.com.

ROD olfo Palazzo dias é doutorando do Programa de Pós-graduação em Sociologia Política da Universidade Federal de Santa Catarina (UFSC).E-mail: rodolfo.dias@gmail.com. 